\title{
Histomorphological Pattern of Cervical Lymphadenopathy
}

\author{
Md. Atiqur Rahman ${ }^{1}$, Md. Mamun Ali Biswas ${ }^{2}$, Syeda Tasfia Siddika ${ }^{3}$, \\ Abdul Mannan Sikder ${ }^{4}$
}

\begin{abstract}
Background: Enlarged palpable cervical lymph nodes as a primary presenting sign are very common and may be due to inflammatory lesions and tumors. Correlation between clinical findings and laboratory data is essential in arriving at a diagnosis. In patients presenting with cervical lymphadenopathy, excision biopsy provides material to establish an early diagnosis. We designed this study in our population for histological evaluation of cervical lymph node biopsies that might be important in the management of these patients. Objective: Histopathological evaluation of different diseases involving the cervical lymph nodes in relation to age and sex of the study population. Materials and Methods: It was a cross sectional study conducted in the department of Pathology, Enam Medical College \& Hospital, Savar, Dhaka during the period from January 2006 to December 2010. A total of 107 patients were evaluated for specific cause of cervical lymphadenopathy in relation to age and sex. Lymph node biopsies of all patients of both sexes and all age groups were included in the study. Results: Among the 107 subjects 58 (54.2\%) were males and 49 (45.8\%) were females with a male to female ratio of 1.2:1. The age of the patients ranged from 2 to 85 years with a mean age of $32.68 \pm 18.01$ years. Of the 107 lymph node biopsies, 34 cases (31.8\%) were reactive lymphadenitis, 41 cases (38.3\%) were tuberculosis, 2 cases (1.9\%) were non-caseous granuloma, 6 cases (5.6\%) were Hodgkin lymphoma, 8 cases (7.5\%) were non-Hodgkin lymphoma, 12 cases (11.2\%) were metastatic neoplasm and 4 cases $(3.7 \%)$ were other specific lesions. Conclusion: The commonest cause of cervical lymphadenopathy was tuberculosis, followed by reactive lymphadenitis, lymphoma and metastatic neoplasm.
\end{abstract}

Key words: Cervical lymphadenopathy, Tuberculosis, Hodgkin lymphoma, Non-Hodgkin lymphoma, Metastatic neoplasm

J Enam Med Col 2013; 3(1): 13-17

\section{Introduction}

Lymph nodes form an important part of body's immune mechanism. Lymphadenopathy refers to any disease process involving lymph nodes that are abnormal in size and consistency. Lymphadenopathy can involve different age groups and any site of the body. Several studies on peripheral lymphadenopathy in various countries have shown that cervical lymph nodes are the most frequently enlarged and biopsied nodes of all peripheral lymph nodes. ${ }^{1,2}$

Cervical lymphadenopathy is usually defined as cervical lymph nodal tissue measuring more than 1 $\mathrm{cm}$ in diameter. ${ }^{3}$ This can be presented as isolated or as a part of generalized lymphadenopathy. Enlarged palpable cervical lymph node as a primary presenting sign is a very common problem in clinical practice. Such lymphadenopathy may be due to acute or chronic inflammation, a primary malignancy of the lymphoid system, a metastasis from an occult

1. Associate Professor, Department of Pathology, Enam Medical College, Savar, Dhaka

2. Assistant Professor, Department of Pathology, Enam Medical College, Savar, Dhaka

3. OSD, DGHS, Mohakhali, Dhaka

4. Professor, Department of Pathology, Enam Medical College, Savar, Dhaka

Correspondence Md. Atiqur Rahman,Email: mdatiq07@gmail.com 
primary malignancy or non-specific hyperplasia. ${ }^{1}$ It cannot be easily diagnosed on clinical grounds or by routine laboratory investigations alone.

For assessment of cervical lymphadenopathy, different modalities of investigations are used which include fine needle aspiration cytology (FNAC), automatic core needle biopsy, flow cytometry, radiologically guided core needle biopsy and open biopsy. ${ }^{4-7}$ Lymph node excision or FNAC as a therapeutic and diagnostic measure to determine the etiology of the underlying illness has long been a practice. FNAC is often the first line of investigation (screening test) used in cases of lymphadenopathy to differentiate between lymphoreticular malignancy, metastatic cancer, specific infections such as tuberculosis, and nonspecific reactive lymphadenitis. ${ }^{8,9}$ The distinction between reactive and malignant lymphoid prolife-rations is the most difficult aspect in lymph node FNAC. For detailed subtyping of certain disease entities such as lymphoma, surgical biopsy for histological studies is required. Lymph node biopsy is also important for clinical staging as well as predicting prognosis in malignant disease. ${ }^{10}$

Due to the high frequency of non-specific, benign, self-limited lymphadenopathy, the number of patients requiring a diagnostic or therapeutic surgical biopsy is correspondingly low. ${ }^{11}$ To confirm the histopathological diagnosis, the excision biopsy should be performed on the largest and firmest node that is palpable, and the node should be removed intact with capsule. ${ }^{12}$

The aim of this study was to determine the overall prevalence of various causes responsible for cervical lymphadenopathy. Study was also carried out to know the distribution of various lesions among the different age groups in both sexes.

\section{Materials and Methods}

The present study was conducted at the department of Pathology, Enam Medical College \& Hospital, Savar, Dhaka during the period from January 2006 to December 2010. A total of 107 patients, both male and female of all age groups, having enlarged cervical lymph nodes were included in this study. Cases with known malignant illness were not included.

A brief history was taken and evaluation of baseline investigations, like complete blood count, ESR, Mantoux test and chest radiography were carried out. Excision biopsy was done in every case. The specimens were fixed in $10 \%$ formalin for 24 hours, after recording the gross morphological features. The size, shape, color, and consistency of the nodes, as well as the presence of necrosis and matting, appearance on cut section, and appearance of the capsule were noted. The nodes were sectioned at $5 \mathrm{~mm}$ intervals and submitted for processing. Four- to five-micron thick sections were cut with a microtome, and stained with hematoxylin and eosin. Special stains, such as Ziehl-Neelsen and periodic acid-Schiff were employed whenever indicated. Diagnosis of tuberculosis was confirmed by demonstration of epithelioid granuloma with caseation necrosis on histopathological examination.

\section{Results}

A total of 107 cervical lymph node biopsies were obtained constituting $56 \%$ of the total number of lymph node biopsies received in the department of Pathology, Enam Medical College \& Hospital, Savar, Dhaka during the five year period of study (2006-2010). There were 58 (54.2\%) males and 49 (45.8\%) females with male to female ratio of $1.2: 1$. The age of the patients ranged from 2 to 85 years with a mean age of $32.68 \pm$ 18.01 years. The mean age of male patients was $32.9 \pm 21.15$ years and that of females was $32.43 \pm 13.61$ years. Most of the patients were in the $3^{\text {rd }}$ decade $(17.8 \%)$ followed by $4^{\text {th }}$ decade $(19.6 \%)$ and $2^{\text {nd }}$ decade $(17.8 \%)$ of life (Figure 1). Majority of the patients $(n=66 ; 61.7 \%)$ were between $11-40$ years of age. Non-neoplastic lesions were common in relatively youngers (mean age $28.75 \pm 15.09$ years) and malignant lesions were common in the older (mean age $44.12 \pm 21$ years).

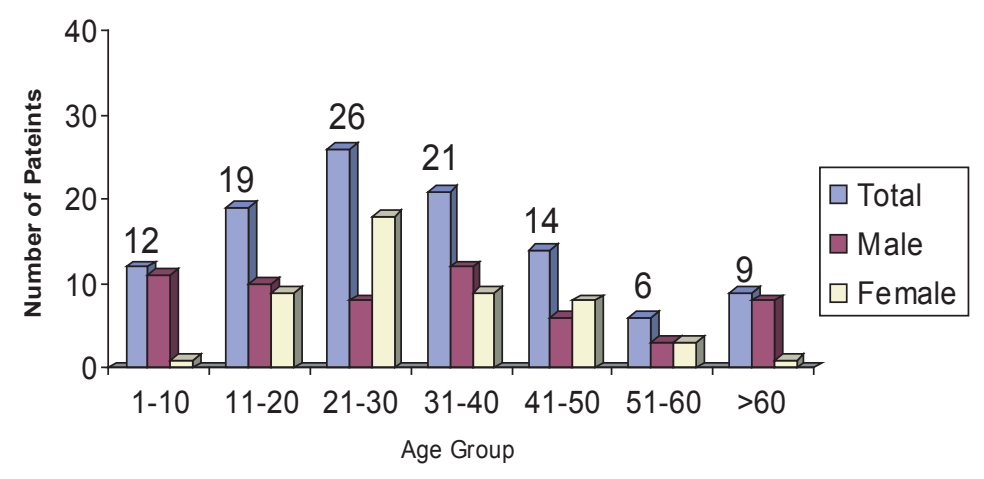

Fig 1. Age and sex distribution of the patients 
Of the 107 lymph node biopsies, 81 cases $(75.7 \%)$ were non-neoplastic lesions and 26 cases $(24.3 \%)$ were malignant. Of the non-neoplastic lesions, 34 cases $(31.8 \%)$ were reactive lymphadenitis, 41 (38.3\%) tuberculosis, $2 \quad(1.9 \%)$ non-caseous granuloma and 4 cases $(3.7 \%)$ were other specific lesions. Among the malignant lesions, 6 cases $(5.6 \%)$ were Hodgkin lymphoma (HL), 8 were $(7.5 \%)$ nonHodgkin lymphoma (NHL) and 12 cases (11.2\%) were metastatic neoplasm (Tables I, II). In this study, mostly posterior cervical lymph nodes were found involved $(\mathrm{n}=48 ; 45 \%)$, followed by upper deep cervical group of lymph nodes. chronic non-specific lymphadenitis and $4(11.8 \%)$ were sinus histiocytosis.

Among the malignant lesions, lymphomas were more common accounting 53.8\% and metastatic carcinoma comprised $46.2 \%$. Malignant lesions were predominantly observed in males. Of the NHLs, intermediate and high grade types were found in six and two cases respectively. Mixed cellularity was the most common subtype among the HLs, seen in five cases and one case was lymphocyte predominant. Among the various types of tumors metastasizing the cervical lymph nodes, squamous cell carcinoma was the commonest, found in 4 cases $(33 \%)$, followed by

Table I: Histological diagnosis in different age groups in both sexes $(\mathrm{N}=107)$

\begin{tabular}{|c|c|c|c|c|c|c|c|c|c|c|c|c|c|c|}
\hline \multirow{3}{*}{$\begin{array}{l}\text { Age } \\
\text { range } \\
\text { (years) }\end{array}$} & \multicolumn{8}{|c|}{ Non-neoplastic lesions $(\mathrm{n}=81 ; 75.7 \%)$} & \multicolumn{6}{|c|}{ Neoplastic lesions ( $\mathrm{n}=26 ; 24.3 \%)$} \\
\hline & \multicolumn{2}{|c|}{ Reactive } & \multicolumn{2}{|c|}{$\mathrm{TB}$} & \multicolumn{2}{|c|}{$\begin{array}{l}\text { Non-caseous } \\
\text { granuloma }\end{array}$} & \multicolumn{2}{|c|}{$\begin{array}{l}\text { Other } \\
\text { lesions }\end{array}$} & \multicolumn{2}{|c|}{$\mathrm{HL}$} & \multicolumn{2}{|c|}{ NHL } & \multicolumn{2}{|c|}{$\begin{array}{l}\text { Metastatic } \\
\text { neoplasm }\end{array}$} \\
\hline & M & $\mathrm{F}$ & $\mathrm{M}$ & $\mathrm{F}$ & $\mathrm{M}$ & $\mathrm{F}$ & M & $\mathrm{F}$ & M & $\mathrm{F}$ & $\mathrm{M}$ & $\mathrm{F}$ & M & $\mathrm{F}$ \\
\hline $1-10$ & 8 & 1 & 1 & & & & & & & & 2 & & & \\
\hline $11-20$ & 3 & 1 & 4 & 6 & & 1 & 1 & 1 & & & 1 & & 1 & \\
\hline $21-30$ & 2 & 6 & 6 & 9 & & & & 1 & & & & & & 2 \\
\hline $31-40$ & 1 & 2 & 3 & 6 & & & & 1 & 2 & & 1 & & 4 & \\
\hline $41-50$ & 3 & 4 & 1 & 3 & & & & & & & 1 & 1 & 1 & \\
\hline $51-60$ & & 1 & 1 & & & & & & & & 1 & & 1 & 2 \\
\hline$>60$ & 2 & & & 1 & & & & & 4 & & 1 & & 1 & \\
\hline $\mathrm{M}: \mathrm{F}$ & & & & 1.6 & & & & 3 & & male & & & & \\
\hline
\end{tabular}

$\mathrm{M}=$ Male, $\mathrm{F}=$ Female, $\mathrm{TB}=$ Tuberculosis, $\mathrm{HL}=$ Hodgkin Lymphoma, $\mathrm{NHL}=$ Non-Hodgkin Lymphoma

Tuberculosis was the most common cause of cervical lymphadenopathy. Females were more frequently affected compared with males with a female to male ratio of $1.6: 1$. Most of the patients $(n=34 ; 83 \%)$ were of 11-40 years. Non-caseous granuloma was seen in only two biopsies.

Reactive lymphadenitis was the second most common cause of lymphadenopathy. Of the 34 lesions, $16(47 \%)$ were follicular hyperplasia, 14 (41\%) were adenocarcinoma in 3, poorly differentiated carcinoma in 2, papillary carcinoma of the thyroid and nasopharyngeal carcinoma in one case each.

Other specific patterns of lymphadenopathies were identified in four cases - three cases of Kikuchi's necrotizing lymphadenitis and one case had necrotic foci with neutrophils suggestive of cat-scratch disease (Table I).

Table II: Diagnosis of the cervical lymph node lesions in two sexes

\begin{tabular}{l|c|c|c|c|c|c|c}
\hline Age & Reactive & TB & $\begin{array}{c}\text { Non } \\
\text { caseous } \\
\text { granuloma }\end{array}$ & HL & NHL & Metastatic & $\begin{array}{c}\text { Other } \\
\text { lesions }\end{array}$ \\
\hline Males & $19(17.8 \%)$ & $16(15 \%)$ & $1(0.9 \%)$ & $6(5.6 \%)$ & $7(6.5 \%)$ & $8(7.4 \%)$ & $1(0.9 \%)$ \\
\hline Females & $15(14 \%)$ & $25(23.3 \%)$ & $1(0.9 \%)$ & - & $1(0.9 \%)$ & $4(3.7 \%)$ & $3(2.8 \%)$ \\
\hline Total & $34(31.8 \%)$ & $41(38.3 \%)$ & $2(1.8 \%)$ & $6(5.6 \%)$ & $8(7.4 \%)$ & $12(11.1 \%)$ & $4(3.7 \%)$ \\
\hline
\end{tabular}




\section{Discussion}

This study included 107 patients having 58 (54.2\%) males and $49(45.8 \%)$ females with male to female ratio 1.2:1. Similar observations of male predominance was found in another study. ${ }^{13}$ However one study of cervical lymph node shows female predominance over male. ${ }^{14}$ Erikson $\mathrm{M}$ et al ${ }^{15}$ in their study stated that there is no predilection for lymphadenopathy with regards to gender. Studies by Olu-Eddo $\mathrm{AN}^{16}$ and Morad $\mathrm{N}$ et $\mathrm{al}^{17}$ found lymphomas to be more common in males. Our study also revealed that lymphoma affected predominantly the male patients $(93 \%)$. This suggests that though gender is not a risk factor for lymphadenopathy, certain etiology for significant lymphadenopathy is more prevalent in one gender over the other.

The age of the patients ranged from 2 to 85 years with a mean age of $32.68 \pm 18.01$ years. Most of the patients were in the age group of 21-30 years $(17.8 \%)$. Khan AU et $\mathrm{al}^{13}$ in their study found mean age $36.52 \pm 17.37$ years with age range 10 to 75 years. Umer MF et al ${ }^{14}$ reported maximum patients were in the age group of 21-30 years. In the present study, patients' age varied according to the different etiologies. In agreement with other studies, nonneoplastic lesions were common in relatively younger age (mean age $28.75 \pm 15.09$ years) and malignant lesions were common in the older age (mean age $44.12 \pm 21$ years). ${ }^{15,17}$

Posterior cervical lymph nodes were mostly involved (45\%), followed by upper deep cervical group. Study conducted by Khan $\mathrm{AU}$ et $\mathrm{al}^{13}$ also showed that posterior cervical lymph nodes were the commonest and affected $40 \%$ of cases.

In this study, non-neoplastic lesions constituted $75.7 \%$, and neoplastic lesions $24.3 \%$ of all biopsies. Of the non-neoplastic lesions, tuberculosis was the commonest lesions accounting 38.3\%. Posterior triangle of the neck was commonly involved in tuberculosis. Some previous studies revealed high prevalence of tuberculosis in Pakistan, India and Bangladesh. ${ }^{18}$ Study by Khan $\mathrm{AU}^{13}$ found tuberculosis in $33.3 \%$ cases and Umer MF et al ${ }^{14}$ found in $55.4 \%$ cases. The variation of tuberculosis in percentage might be due to geographic prevalence, age and immunological status of the patients. From the last decade the incidence of tuberculosis has been rising in the USA and other Western countries, reflecting the increased risk of the infection in AIDS patients. ${ }^{19}$ In the present study most of the cases of tuberculosis occurred in young females ( $2^{\text {nd }}$ and $3^{\text {rd }}$ decades) and they were $60 \%$ $(n=15)$ of female patients affected with tuberculosis. This finding is consistent with what has been reported by others. ${ }^{20,21}$

Reactive lymphadenitis was the second most common cause and accounts $31.8 \%$. Shaikh SM et al also found reactive lesion as the second most common cause after tuberculosis and it occurred in $24.3 \%$ cases. $^{22}$ In our study, reactive glands were mostly less than $1 \mathrm{~cm}$ in size in $70 \%$ cases, whereas tuberculous and malignant nodes were over $1 \mathrm{~cm}$ in size in $92 \%$ and $94 \%$ cases respectively. Bedi RS et $\mathrm{al}^{23}$ reported lymph nodes over $1 \mathrm{~cm}$ size in reactive, tuberculous and malignant lesions in $28 \%, 90 \%$ and $80 \%$ cases respectively.

In the present series, malignancy occurred in $24.3 \%$ cases with lymphoma $13.1 \%$ and metastatic tumors $11.2 \%$. Other authors also found malignancy in $22.5 \%$ cases, among which lymphoma was the commonest malignancy accounting $12.2 \%{ }^{24}$ In our study, amongst lymphomas $7.5 \%$ patients had NHL and $5.6 \%$ had HL. According to Olu-Eddo AN et $\mathrm{al}^{16}$, NHL was $17.4 \%$ and HL 5.6\%. Wide variable results were seen in medical reports regarding metastatic nodes. The study of Khan $\mathrm{AU}^{13}$ reports $32 \%$, Shaikh SM et al ${ }^{22} 7 \%$, and $\mathrm{Na} \mathrm{DG}^{25} 43.8 \%$ cases.

From this study, it is concluded that cervical lymphadenopathy is a common clinical problem and the commonest cause was tuberculosis followed by reactive hyperplasia, lymphoma and metastatic nodes. Females were more affected by tuberculosis and males were predominantly affected by malignant lesions. The detailed clinical examination and baseline investigations, supplemented by excision biopsy for histopathology is able to diagnose the etiology of enlarged cervical lymph node.

\section{References}

1. Lee Y, Terry R, Lukes RJ. Lymph node biopsy for diagnosis: a statistical study. J Surg Oncol 1980; 14(1): 53-60. 
2. Amr SS, Kamal MF, Tarawneh MS. Diagnostic value of cervical lymph node biopsy: a pathological study of 596 cases. J Surg Oncol 1989; 42(4): 239-243.

3. Shrestha AK, Chalise PR, Shrestha ML. Lymph node biopsies: a hospital based retrospective study. J Nepal Med Assoc 2009; 48: 306-309.

4. Nyquist GG, Tom WD, Mui S. Automatic core needle biopsy: a diagnostic option for head and neck masses. Arch Otolaryngol Head Neck Surg 2008; 134(2): 184189.

5. Kim BM, Kim EK, Kim MJ, Yang WI, Park CS, Park S. Sonographycally guided core needle biopsy of cervical lymphadenopathy in patients without known malignancy. J Ultrasound Med 2007; 26(5): 585-591.

6. Abdullah P, Mubarak A, Zahir N. The importance of lymph node biopsy in diagnosis of lyphadenopathy. J Coll Physicians Surg Pak 2000; 10(8): 298-301.

7. Cannon CR, Richardson LD. Value of flow cytometry in the evaluation of head and neck fine-needle lymphoid aspirates: a 3 year retrospective review of a communitybased practice. Otolaryngol Head Neck Surg 2001; 124(5): 544-548.

8. Das DK, Gupta SK, Datta BN, Sharma SC. Fine needle aspiration cytodiagnosis of Hodgkin's disease and its subtypes. I. Scope and limitations. Acta Cytol 1990; 34(3): 329-436.

9. Gamboa-Dominquez A, Luna-Garcia L, QuintanillaMartinez L. Lymph node biopsy using fine-needle aspiration. Clinical and cytohistological correlation in 179 cases. Rev Invest Clin 1995; 47(1): 35-41.

10. Sun HB, Zheng XF, Zhang J. Diagnostic accuracy of fine needle aspiration biopsy of cervical lymph node: a study of 580 cases. Zhonghua Bing Li Xue Za Zhi 2008; 37(10): 693-697.

11. Soldes O, Younger JG, Hirschl RB. Predictors of malignancy in childhood peripheral lymphadenopathy. J Pediatr Surg 1999; 34(10): 147-152.

12. Majid A. Prevalence of tuberculosis in cervical lymphadenopathy. The Professional 1996; 3: 223-227.

13. Khan AU, Nawaz G, Khan AR, Raza. An audit of 75 cases of cervical lymphadenopathy. J. Med. Sci. 2011; 19: 95-97.
14. Umer MF, Mehdi SH, Muttaqi AE, Hussain SA. Presentation and aetiological aspects of cervical lymphadenopathy at Jinnah Medical College Hospital Korangi, Karachi. Pak J Surg 2009; 25(4): 224-226.

15. Eriksson M, Bennet R, Danielsson N. Non-tuberculous mycobacterial lymphadenitis in healthy children: another "lifestyle disease"? Acta Paediatri 2001; 90(11): 13401342.

16. Olu-Eddo AN, Ohanaka CE. Peripheral lymphadenopathy in Nigerian adults. J Pak Med Assoc 2006; 56(9): 405-408.

17. Morad N, Malatani T, Khan AR, Hussain N. Peripheral lymphadenopathy as a primary presenting sign: a study of 324 cases from Asir region. Annals of Saudi Medicine 1992; 12(1): 72-75.

18. Krishnaswami H, Koshi G, Kulkarni KG, Job CK. Tuberculous lymphadenitis in South India - a histopathological and bacteriological study. Tubercle 1972; 53(3): 215-220.

19. Lee KC, Tami TA, Lalwani AK, Schecter G. A contemporary management of cervical tuberculosis. Laryngoscope 1992; 102(1): 60-64.

20. Rieder HL, Snider DE, Cauthen GM. Extrapulmonary tuberculosis in the United States. Am Rev Respir Dis 1990; 141(2): 347-351.

21. Waldman RH. Tuberculosis and the atypical mycobacteria. Otolaryngol Clin North Am 1982; 15(3): 581-596.

22. Shaikh SM, Baloch I, Bhatti Y, Shah A, Shaikh GS, Deenari RA. An audit of 200 cases of cervical lymphadenopathy. Medical Channel 2010; 16(1): 85-87.

23. Bedi RS, Thind GS, Arora VK. A clinico-pathological study of superficial lymphadenopathy in northern India. Ind J Tub 1987; 34(4): 189-191.

24. Al-Ghaithy ZM, Merdad AA, Meccawy AM. Cervical lymph node biopsies in King Abdul Aziz University Hospital. J KAU Med Sci 1999; 7(2): 29-35.

25. Na DG, Lim HK, Byun HS, Kim HD, Ko YH, Baek JH. Differential diagnosis of cervical lymphadenopathy: usefulness of color Doppler sonography. Am J Roentogenol 1997; 168(5): 1311-1316. 